\title{
Usefulness of the Intrarenal Resistivity Index As A Cardiovascular Risk Marker in Afro-Descendants: An Observational, Cross-Sectional Study
}

Francival Souza ( $\nabla$ francival.souza@uol.com.br)

Federal University of Maranhão Joyce Lages

Federal University of Maranhão

Eliane Magalhaes

Rio de Janeiro State University

Dyego Brito

Federal University of Maranhão

Vinicius Mendes

Federal University of Maranhão

Natalino Filho

Federal University of Maranhão

\section{Research Article}

Keywords: Intrarenal resistivity index, Cardiovascular disease, African descent.

Posted Date: December 18th, 2020

DOI: https://doi.org/10.21203/rs.3.rs-126201/v1

License: (1) This work is licensed under a Creative Commons Attribution 4.0 International License. Read Full License 


\section{Abstract}

Background: Cardiovascular diseases are a major cause of morbidity and mortality in Brazil and worldwide. Stratification of the risk of these diseases in asymptomatic patients using biomarkers can lead to early detection of patients at high risk of cardiovascular disease and promote the prevention of relevant events. The intrarenal resistivity index (IRI) is an imaging test that assesses renal perfusion, systemic hemodynamics, and atherosclerosis. It has been reported that changes in IRI are associated with morbidity and mortality in a population of patients with hypertension, diabetes, and chronic kidney disease. The present study tested a hypothesis that IRI is associated with imaging biomarkers of cardiovascular risk in a population of Afro-descendants.

Methods: A total of 313 Afro-descendants with high cardiovascular risk were assessed using kidney ultrasound, Doppler echocardiography, carotid Doppler, and computed tomography to assess the calcium score. The individuals were divided into Group 1 with normal IRI and Group 2 with high IRI.

Results: The mean intrarenal resistivity index was 0.61 in group 1 and 0.71 in group 2 , and the mean age was 56.9 years, with $53 \%$ being female. Group 2 had significantly greater left ventricular mass, larger left atrium, and a higher prevalence of diastolic dysfunction ( $34.5 \%$ vs. $66.7 \%, p<0.0001$ ). Group 2 also had a significantly higher frequency of carotid plaque ( $31 \%$ vs. $64 \%, p<0.001)$ as well as total coronary artery calcium score and higher frequency of high coronary artery calcium score (56.37 vs. $212.03, p<0.0001$ and $24 \%$ vs. $50 \%$, p $<0.001$, respectively). The presence of diastolic dysfunction with high left atrial pressure, coronary artery calcium score $>0$, and carotid plaque was independently associated with the intrarenal resistivity index.

Conclusions: The intrarenal resistivity index is associated with imaging biomarkers of cardiovascular risk, mainly with the coronary artery calcium score, diastolic dysfunction, and atherosclerotic carotid plaque in people of African descent, with high cardiovascular risk.

\section{Background}

Cardiovascular diseases (CVD) are a major cause of morbidity and mortality in Brazil, and worldwide, ${ }^{1}$ and the increase in its incidence and prevalence in the developing countries has potentially enormous epidemiological implications. Approximately $80 \%$ of all CVD-related deaths occur in low- and middleincome countries and affect younger individuals, leading to a substantial economic impact due to the loss of years of productive life ${ }^{2}$. Hence, clinical strategies aimed at early detection of patients at high risk of CVD and identifying asymptomatic individuals with a higher predisposition to CVD are crucial for the effective prevention and planning of individual therapeutic goals ${ }^{3}$. New markers have been used for cardiovascular risk stratification and include serum and urinary biomarkers, such as ultrasensitive $\mathrm{C}$ Reactive Protein (us-CRP), glomerular filtration rate (GFR), and microalbuminuria; tissue biomarkers or imaging biomarkers assessed by Doppler ultrasound, such as left ventricular hypertrophy, left ventricular 
systodiastolic dysfunction, and carotid artery disease; or biomarkers such as coronary artery calcium (CAC), arterial stiffness, and ankle-brachial index assessed using other imaging technologies ${ }^{4}$.

Epidemiological evidence shows that arterial stiffness is also an important marker in the assessment of cardiovascular risk and an independent predictor of total mortality, cardiovascular mortality, fatal and non-fatal coronary events, and fatal stroke ${ }^{5}$. Renal hemodynamics, assessed using the intrarenal resistivity index (IRI), strongly correlate with the parameters of assessment of arterial stiffness, such as aortic pulse pressure, aortic incident pressure wave, aortic augmented pressure, and pulse wave velocity. This correlation remains highly significant after considering confounders including, age, cholesterol, glycosylated hemoglobin, and GFR ${ }^{6}$.

The evaluation of microvascular flow in different regions of the renal parenchyma allows the calculation of the intrarenal resistivity index. The IRI was introduced in 1950 and was initially proposed as a semiquantitative assessment of intrarenal vascular resistance. In 1974, Pourcelot ${ }^{7}$ described the $^{-1}$ resistance index or Pourcelot index that reflected the vascular resistance distal to the evaluation point. Normal IRI values in adults vary from 0.47 to 0.70 , with a small difference of 5 to $8 \%$ between the kidneys. The IRI varies between the sexes, being higher in women, and increases progressively with age, even in healthy individuals ${ }^{8}$.

Recent data indicate that the IRI not only reflects changes in renal perfusion, but is also associated with systemic hemodynamic changes and atherosclerosis. Hence, in the last two decades, interest in the study of renal hemodynamics in the context of cardiovascular risk has increased. Studies have shown a significant association between IRI and arterial stiffness in hypertensive patients and the general population $^{9-13}$, as well as an association between IRI and target organ damage in hypertensive individuals ${ }^{14-16}$. In patients with Diabetes Mellitus (DM), a change in IRI is associated with worsening renal function and increased risk of macroalbuminuria ${ }^{17-18}$, in addition to an increased risk of microvascular complications such as nephropathy, retinopathy, and neuropathy ${ }^{19}$.

Furthermore, in patients with chronic kidney disease (CKD), IRI is associated with increased cardiovascular risk. Heine et al. ${ }^{20}$ evaluated a group of patients with CKD and demonstrated a significant association of IRI with Framingham risk score and atherosclerosis, which could potentially explain the greater morbidity and mortality in this population. A recent study has shown that in individuals with nondialysis CKD, elevated IRI is positively associated with the presence of DM and high LDL cholesterol and negatively associated with the glomerular filtration rate and with the use of angiotensin-converting enzyme inhibitors. In this study, the authors suggest that the use of these drugs might suppress the elevation of IRI.

The prevalence of cardiovascular disease varies by ethnicity. For example, stroke, heart failure, and renal failure are more common in the Afro-descendant population and occur earlier in the natural course of the disease ${ }^{22-23}$. Hypertensive nephropathy is an important health concern among the Afro-descendant 
population; however, studies evaluating the importance of IRI as a marker of cardiovascular risk in this population are scarce.

The main hypothesis of the present study is that the IRI is an imaging biomarker of cardiovascular risk in the Afro-descendant population. Thus, the objective of this study was to evaluate the association of IRI with imaging biomarkers of cardiovascular risk in isolated communities of Brazilian Afro-descendants with high cardiovascular risk.

\section{Methods}

\section{Study Design}

The sample population of the present study comprised individuals above 18 years of age, selected by probabilistic sampling to participate in the PREVRENAL population study between August 2012 and April 2013, to estimate the prevalence of CKD in Brazilian Afro-descendants from isolated communities. The study design has been previously described ${ }^{24}$. Thus, 1,539 people from the 32 remaining quilombo communities were selected for the study. People under 18 years of age, pregnant women, patients with a chronic consumptive disease (cancer in treatment or acquired immunodeficiency syndrome), hematological disease (lymphoproliferative), autoimmune disease, infection (systemic, genitourinary tract), chronic and/or acute kidney disease undergoing dialysis, taking immunosuppressants, and having thyroid disorders.

A sample of 398 individuals diagnosed with systemic arterial hypertension, diabetes mellitus type 2 , albuminuria, or GFR less than $60 \mathrm{~mL} / \mathrm{min} / 1.73 \mathrm{~m}^{2}$ was subjected to cardiovascular imaging tests. The cardiovascular imaging tests performed were transthoracic echocardiography, carotid duplex scan, chest computed tomography, and renal Doppler ultrasound. Among the individuals selected for imaging exams, 313 underwent and completed the renal Doppler ultrasound and thus made up the final sample of this study. Carotid duplex scan was performed in 307 individuals, 304 underwent a Doppler echocardiography, and 245 underwent a chest multidetector computed tomography (Fig. 1).

\section{Data collection}

Clinical data were collected through a questionnaire given to each household to obtain demographic information: gender, age, and ethnicity; lifestyle habits (smoking and drinking); and medical history (diabetes mellitus and systemic arterial hypertension). Weight was measured on an electronic scale with a capacity of up to $150 \mathrm{~kg}$ and a variation of $50 \mathrm{~g}$. The height was measured in duplicate, using a portable anthropometer with a variation of $0.1 \mathrm{~cm}$ (allowing a maximum variation of $0.5 \mathrm{~cm}$ between two measurements and calculating the average). The Body Mass Index (BMI) was defined as the weight (kg) divided by the square of the height in meters. The blood pressure assessment was performed following the VII Brazilian Guidelines for Hypertension, using the average of two measurements, measured on the right arm, with a 3-minute interval, using the oscillometric method with the Omron 705-IT device already 
validated. Individuals who reported being hypertensive or who had systolic pressure $\geq 140 \mathrm{mmHg}$ or diastolic pressure $\geq 90 \mathrm{mmHg}$ were considered hypertensive.

Blood and urine samples were collected after a 12-hour fast. Serum creatinine, cystatin C, glycemia, triglycerides, albumin, total cholesterol and fractions, creatinine, and albumin were measured in an isolated urine sample. The albumin/creatinine ratio was calculated. Creatinine clearance was estimated using the CKD-EPI (Chronic Kidney Disease Epidemiology Collaboration) equation that includes age, sex, and race ${ }^{25}$.

Individuals with known diabetes mellitus or with glycemia more than $126 \mathrm{mg} / \mathrm{dL}$ in two samples were considered to have diabetes mellitus. Chronic kidney disease was defined as a creatinine clearance below $60 \mathrm{~mL} / \mathrm{min} / 1,73 \mathrm{~m}^{2}$.

Doppler echocardiography was performed with the patient in the left lateral position, using the Vingmed GE ultrasound device, model VIVID i (Horten, Norway), with second harmonic and sectoral electronic transducer 2 to $4 \mathrm{MHz}$. The cardiac evaluation included cardiac dimensions, ventricular geometry, and ejection fraction by the Teicholz method. Presence of diastolic dysfunction was considered in individuals with reduced ejection fraction, myocardial disease, or clinical evidence of diastolic dysfunction ${ }^{26}$. The mean left atrial pressure (LAP) was estimated and considered high when at least 2 out of the following 3 criteria were present: Average E/e' ratio $>14$, tricuspid regurgitation velocity $>2.8 \mathrm{~m} / \mathrm{s}$, and left atrium (LA) volume index $>34 \mathrm{~mL} / \mathrm{m}^{2}$.

Duplex scan of the carotid arteries was performed with a Vingmed GE ultrasound device, model logiq p6, with a linear transducer from 7 to $10 \mathrm{MHz}$. With the patient in a supine position and the head slightly extended and tilted to the opposite side, the common carotid artery, carotid bifurcation, and internal and external carotid arteries were evaluated on both sides. Atheromatous carotid plaque was defined as a focal structure extending at least $0.5 \mathrm{~mm}$ into the vessel lumen, and/or measuring more than $50 \%$ of the value of the adjacent carotid intima-media thickness (CIMT), and/or an CIMT greater than $1.5 \mathrm{~mm}$ in any of the analyzed arteries (common, bifurcation, and internal) ${ }^{27}$.

The CAC score was evaluated using chest multidetector computed tomography (64 channels) with $3 \mathrm{~mm}$ serial cuts across the heart synchronized with the electrocardiogram. Coronary calcification was calculated from the weighted sum of densities above $130 \mathrm{HU}$ (Agatston score) ${ }^{28}$. Individuals with CAC scores above 0 (zero) Agatston units were considered to have coronary calcification.

Renal Doppler ultrasound was performed with a Vingmed GE ultrasound device, model logiq p6, with a 3 to $4 \mathrm{MHz}$ convex transducer. The patient was placed in a supine position, and the size of the right and left kidneys, as well as the velocity of flow in the renal arteries, were evaluated to detect morphological abnormalities and/or stenosis of the renal arteries. The intrarenal arteries were identified by color flow mapping, and analysis was performed with pulsed Doppler to obtain the peak systolic (Vmax) and diastolic (Vmin) velocity, and the index was calculated using the formula: (Vmax-Vmin)/Vmax. The IRI 
was calculated in three different segments of each kidney, and the overall IRI was calculated as the average of the measurements performed in the upper, middle, and lower segments of both kidneys ${ }^{29}$.

\section{Statistical analysis}

After data collection, the study population was divided into 2 groups according to the IRI value and sex, since females have higher IRI values in the general population and healthy individuals, which may be attributed to hormonal differences ${ }^{10}$. Group 1 : individuals with normal IRI values (less than the median according to the sex) and Group 2: individuals with altered IRI (greater than the median according to the sex). Clinical and laboratory variables, presence of plaque in the carotid arteries, CAC score, and Doppler echocardiography parameters were compared between these two groups.

For comparisons between the two groups, the unpaired t-test and Mann-Whitney test were used when appropriate for numerical variables, and the chi-square test was used for categorical variables. The Shapiro Wilk test was used to assess the normality of the distribution of the numerical variables.

Imaging biomarkers that showed $p<0.20$ in the univariate analysis were considered in the stepwise logistic regression model. Only variables with a $p$-value $<0.05$ remained in the final model. Data were analyzed using the STATA 12.0 statistical program.

\section{Considerations on ethical aspects}

This study is being conducted in accordance with the principles established by the 18th World Medical Assembly (Helsinki, 1964) and all subsequent amendments. The study was approved by the Research Ethics Committee of the University Hospital of the Federal University of Maranhão ( ${ }^{\circ}$ 41,492/2012). Written informed consent for participation in the study was obtained from all participants.

\section{Results}

\section{Clinical characteristics and intrarenal resistance index.}

The mean IRI was 0.66 , being 0.61 in group 1 and 0.71 in group $2(p<0.0001)$. The clinical and demographic characteristics of the study participants and the corresponding relationships with their IRI are shown in Table 1. In the total study population, the mean age was 56.9 years, $53 \%$ were female, and the mean BMI was $25.78 \mathrm{~kg} / \mathrm{m}^{2}$. Hypertension was present in $71.25 \%$ of individuals, diabetes mellitus in $15.57 \%, 11.5 \%$ were smokers, and $80 \%$ declared themselves as Afro-descendant (black or mulato).

In the univariate analysis, age, body mass index, systolic blood pressure, pulse pressure, cystatin $\mathrm{C}$, and LDL cholesterol were significantly higher in group 2. However, the mean values of us-CRP and GFR were lower in group $2(p<0.05)$. Prevalence of hypertension and diabetes mellitus and the albumin/creatinine ratio were not significantly associated with IRI. 
Table 1

Clinical characteristics and IRI of the study subjects.

\begin{tabular}{|c|c|c|c|c|}
\hline & $\begin{array}{l}\text { Total }(n= \\
313)\end{array}$ & $\begin{array}{l}\text { Group } 1(n= \\
170)\end{array}$ & $\begin{array}{l}\text { Group } 2(n= \\
143)\end{array}$ & p-value* \\
\hline Intrarenal resistivity index (IRI) & $0.66 \pm 0.06$ & $0.61 \pm 0.03$ & $0.71 \pm 0.04$ & $\begin{array}{l}< \\
0.0001\end{array}$ \\
\hline Age (years) & $56.98 \pm 15.71$ & $49.82 \pm 14.47$ & $65.48 \pm 12.61$ & $\begin{array}{l}< \\
0.0001\end{array}$ \\
\hline Female (\%) & 53.04 & 50.59 & 55.94 & 0.34 \\
\hline Black/mulatto ethnicity (\%) & 87.22 & 85.29 & 89.51 & 0.26 \\
\hline Body mass index $\left(\mathrm{kg} / \mathrm{m}^{2}\right)$ & $25.78 \pm 4.82$ & $26.42 \pm 4.36$ & $25.02 \pm 5.22$ & 0.0037 \\
\hline Arterial hypertension (\%) & 71.25 & 68.24 & 74.83 & 0.199 \\
\hline Diabetes Mellitus (\%) & 17.57 & 15.29 & 20.28 & 0.24 \\
\hline $\begin{array}{l}\text { Systolic blood pressure } \\
(\mathrm{mmHg})\end{array}$ & $\begin{array}{l}144.69 \pm \\
26.27\end{array}$ & $137.71 \pm 22.41$ & $152.99 \pm 28.12$ & $\begin{array}{l}<.0001 \\
0 .\end{array}$ \\
\hline $\begin{array}{l}\text { Diastolic blood pressure } \\
(\mathrm{mmHg})\end{array}$ & $82.90 \pm 13.29$ & $84.40 \pm 13.40$ & $81.12 \pm 12.99$ & 0.052 \\
\hline Pulse pressure (mmHg) & $61.79 \pm 19.60$ & $53.31 \pm 13.17$ & $71.86 \pm 21.19$ & $\begin{array}{l}<.0001 \\
0.01\end{array}$ \\
\hline Smoking (\%) & 11.50 & 10.00 & 13.29 & 0.31 \\
\hline Cystatin C (mg/L) & $0.94 \pm 0.20$ & $0.89 \pm 0.18$ & $1.00 \pm 0.20$ & $\begin{array}{l}<.0001 \\
0\end{array}$ \\
\hline Fasting glycemia (mg/dL) & $\begin{array}{l}118.67 \pm \\
51.76\end{array}$ & $116.94 \pm 50.75$ & $120.73 \pm 53.03$ & 0.17 \\
\hline HDL cholesterol (mg/dL) & $48.29 \pm 14.06$ & $47.60 \pm 13.85$ & $49.11 \pm 14.31$ & 0.28 \\
\hline LDL cholesterol (mg/dL) & $\begin{array}{l}132.26 \pm \\
44.36\end{array}$ & $127.65 \pm 45.81$ & $137.70 \pm 42.11$ & 0.016 \\
\hline Triglycerides (mg/dL) & $\begin{array}{l}150.76 \pm \\
97.27\end{array}$ & $153.20 \pm 107.45$ & $147.86 \pm 83.86$ & 0.69 \\
\hline us-CRP mg/L) & $0.74 \pm 3.58$ & $0.80 \pm 4.63$ & $0.67 \pm 1.62$ & 0.033 \\
\hline Albuminuria/creatinine (mg/g) & $\begin{array}{l}56.77 \pm \\
371.17\end{array}$ & $40.08 \pm 132.52$ & $76.52 \pm 373.66$ & 0.08 \\
\hline Albuminuria/creatinine > $30(\%)$ & 20.65 & 19.64 & 21.83 & 0.635 \\
\hline Creatinine clearance $(\mathrm{ml} / \mathrm{min})$ & $95.65 \pm 22.28$ & $100.30 \pm 23.72$ & $90.13 \pm 19.08$ & 0.0003 \\
\hline
\end{tabular}

us-CRP = ultra-sensitive C-reactive protein Group $1=$ intrarenal resistance index $\leq$ than the average for the sex. Group 2 = intrarenal resistance index $>$ than the average for the sex. * $p$-value between groups 1 and 


\section{Relationship between imaging biomarkers and IRI.}

The relationship between the Doppler echocardiographic parameters and the IRI in the univariate analysis is shown in Table 2. Group 2 showed significantly greater LV mass, larger left atrium, and a higher frequency of LV hypertrophy. On the tissue Doppler, the wave e' in the lateral mitral ring and the septal ring was significantly lower in group 2, while the mean E/e' ratio was higher in group 2 . The frequency of diastolic dysfunction was also higher in group $2(34.5 \%$ vs. $66.7 \%, p<0.0001)$.

Table 2

Doppler echocardiographic parameters and intrarenal resistance index.

\begin{tabular}{|c|c|c|c|c|}
\hline $\begin{array}{l}\text { Doppler echocardiography } \\
\text { parameters }\end{array}$ & $\begin{array}{l}\text { Total }(n= \\
304)\end{array}$ & $\begin{array}{l}\text { Group } 1(n= \\
200)\end{array}$ & $\begin{array}{l}\text { Group } 2(n= \\
104)\end{array}$ & $\begin{array}{l}\text { p- } \\
\text { value* }\end{array}$ \\
\hline Heart rate (bpm) & $\begin{array}{l}63.17 \pm \\
12.19\end{array}$ & $63.61 \pm 12.24$ & $62.63 \pm 12.16$ & 0.17 \\
\hline LV diastolic diameter (mm) & $48.51 \pm 5.12$ & $48.59 \pm 4.97$ & $48.41 \pm 5.31$ & 0.76 \\
\hline LA diameter (mm) & $37.25 \pm 5.45$ & $36.56 \pm 5.09$ & $38.08 \pm 5.77$ & 0.012 \\
\hline Ejection fraction (\%) & $67.61 \pm 8.15$ & $67.05 \pm 8.70$ & $68.28 \pm 7.38$ & 0.51 \\
\hline LV mass index $\left(\mathrm{g} / \mathrm{m}^{2}\right)$ & $\begin{array}{l}99.62 \pm \\
25.80\end{array}$ & $95.97 \pm 25.98$ & $104.06 \pm 24.95$ & 0.0006 \\
\hline LV hypertrophy (\%) & 36.10 & 30.00 & 43.36 & 0.014 \\
\hline LA volume index $\left(\mathrm{ml} / \mathrm{m}^{2}\right)$ & $\begin{array}{l}32.40 \pm \\
10.10\end{array}$ & $30.81 \pm 9.77$ & $34.34 \pm 10.19$ & 0.0005 \\
\hline Septal ring e' wave $(\mathrm{cm} / \mathrm{s})$ & $7.16 \pm 3.05$ & $8.17 \pm 3.28$ & $5.93 \pm 2.21$ & $<0.0001$ \\
\hline Lateral ring e' wave $(\mathrm{cm} / \mathrm{s})$ & $9.72 \pm 4.08$ & $11.22 \pm 4.07$ & $7.89 \pm 3.27$ & $\begin{array}{l}< \\
0.0001\end{array}$ \\
\hline Mean E/e' ratio & $9.07 \pm 3.83$ & $8.03 \pm 3.61$ & $10.34 \pm 3.73$ & $<0.0001$ \\
\hline Diastolic dysfunction (\%) & 49.32 & 34.50 & 66.67 & $<0.0001$ \\
\hline High LAP (\%) & 17.65 & 10.00 & 28.57 & 0.001 \\
\hline
\end{tabular}

$\mathrm{LA}=$ left atrium LV = left ventricle. LAP = left atrial pressure. Group $1=$ intrarenal resistance index $\leq$ than the average for gender. Group $2=$ intrarenal resistance index $>$ than the average for the sex.. * $\mathrm{p}$-value between groups 1 and 2 .

Carotid duplex scan was performed on all 307 individuals in the study. The frequency of carotid plaque was $46.33 \%$ in the total group, with $31.18 \%(n=53)$ in group 1 and $64.34 \%(n=92)$ in group $2(p<$ 
0.0001).

Table 3 presents the data of the CAC score and IRI. The total CAC score and the frequency of high CAC score was significantly higher in group 2 ( $56.85 \pm 283.37$ vs. $212.03 \pm 522, p<0.0001$ and $24.06 \%$ vs. $50.00 \%, p<0.0001$, respectively).

Table 3

Coronary calcium score and intrarenal resistance index.

\begin{tabular}{|lllll|}
\hline CAC score & Total $(n=245)$ & Group 1 $(n=157)$ & Group 2 $(n=88)$ & p-value* \\
\hline Total CAC score (U Agatston) & $127.79 \pm 416.69$ & $56.85 \pm 283.37$ & $212.03 \pm 522$ & $<0.0001$ \\
\hline High CAC score (\%) & 35.92 & 24.06 & 50.00 & $<0.0001$ \\
\hline $\begin{array}{l}\text { CAC = coronary artery calcium. Group 2 = intrarenal resistance index }>\text { than the average for the sex. * } \\
\text { p-value between groups 1 and 2. }\end{array}$ & & & \\
\hline
\end{tabular}

The stepwise multivariate logistic regression analysis was performed using the following parameters: LV mass index, LV hypertrophy, high LAP, carotid plaque, CAC score (total value), and CAC score $>0$ and is demonstrated in Table 4. The presence of high LAP, CAC score $>0$, and a carotid plaque was independently associated with a change in IRI.

Table 4

Cardiovascular risk imaging biomarkers associated with altered IRI by stepwise logistic regression analysis

\begin{tabular}{|lllll|}
\hline Variables & Odds Ratio & Z statistics & p-value & Confidence interval (95\%) \\
\hline CAC score $>0$ & 2.31 & 2.09 & 0.037 & $1.05-5.10$ \\
\hline Carotid plaque & 2.57 & 2.44 & 0.015 & $1.20-5.48$ \\
\hline High LAP & 3.08 & 2.38 & 0.037 & $1.22-7.78$ \\
\hline
\end{tabular}

\section{Discussion}

The present study evaluated a population of 313 Afro-descendant subjects with high cardiovascular risk, defined as the presence of arterial hypertension, diabetes mellitus, albuminuria, and non-dialysis CKD. It demonstrated that evaluation of IRI in the stratification of cardiovascular risk could be useful in clinical practice.

Studies evaluating the importance of IRI as a cardiovascular risk marker in populations of Afrodescendants are scarce in the literature. Recently, a study conducted in an African population demonstrated that IRI was higher in hypertensive black patients than in hypertensive Caucasian patients, probably due to the genetic and environmental differences ${ }^{30}$. The present study showed a significant association between IRI and the imaging biomarkers for cardiovascular risks, such as LV mass index, frequency of LV hypertrophy, diastolic function parameters assessed by tissue Doppler, CAC score, and carotid atherosclerotic disease. In multivariable logistic regression analysis, IRI was independently 
associated with atherosclerosis biomarkers such as atherosclerotic carotid plaque and CAC score, and with high LAP (diastolic dysfunction $\geq$ moderate).

The association of IRI with atherosclerosis has been reported in the literature. CIMT, a measure of subclinical atherosclerosis, is independently associated with IRI in individuals with systemic arterial hypertension ${ }^{12,14-15,31}$, and in those with CKD $^{18}$. Geraci and colleagues ${ }^{32}$ evaluated 263 hypertensive individuals by performing Doppler ultrasound of the carotid and renal arteries. The IRI increased progressively with the increase in the severity of carotid atherosclerosis, and this association remained significant even after adjusting for confounding variables. IRI was an independent predictor of a moderate to high SINYAX score in a study evaluating 235 patients with an acute coronary syndrome who underwent angiography and renal Doppler. Thus, the non-invasive assessment of IRI proved to be associated with the extension and complexity of CAD (coronary artery disease) ${ }^{33}$. More recently, it was demonstrated that elevated IRI and left main coronary artery injury was associated with a worse prognosis in a patient with CAD referred for an angiography ${ }^{34}$.

Arterial compliance is the primary determinant of arterial pulsatility. Arterial stiffness associated with age and other cardiovascular risk factors increases pulsatile stress, causing endothelial injury and damage to the smooth muscle cells in the arteries of high-flow organs such as the kidneys ${ }^{35}$. Therefore, arterial stiffness seems to be the main link between renal hemodynamics and atherosclerosis. In the present study, the presence of atherosclerosis was defined as the presence of an atherosclerotic carotid plaque, which corroborates with previous studies. We observed an association between the presence of carotid plaque and IRI, regardless of other cardiovascular risk imaging biomarkers.

Regarding diastolic dysfunction, Maclsaac and colleagues ${ }^{36}$ evaluated 167 patients with type 2 diabetes mellitus and demonstrated that IRI was associated with markers of diastolic dysfunction. The association was independent of systolic function, hypertension, presence and severity of renal dysfunction, and other potentially confounding variables. In the present study, no independent association was observed between LV mass index or frequency of left ventricular hypertrophy with IRI; however, an independent association between high LAP and high IRI was seen, indicating a relationship between the increase in intrarenal vascular resistance and LAP elevated. In addition, the findings of the present study and data from previous studies suggest that the development of vascular and myocardial stiffness are manifestations of a common pathophysiological mechanism, not only present in the diabetic population.

The CAC score is an independent predictor of cardiovascular disease, including coronary heart disease. A study that evaluated the new risk markers in the assessment of cardiovascular risk showed that the CAC score, ankle-brachial index, us-CRP, and family history were independent predictors of cardiovascular events in individuals at intermediate risk; however, the CAC score had higher risk discrimination and reclassification than other markers ${ }^{37}$. The present study demonstrated, for the first time, an independent association between CAC score and elevated IRI. Recently, a study evaluating hypertensive individuals demonstrated a strong association between calcification of the aortic arch and IRI, whose 
pathophysiological mechanism could be potentially common with that of coronary calcification, which is, reduced vascular compliance and increased arterial stiffness ${ }^{38}$.

The evaluation of renal hemodynamics can be performed by Doppler of the intrarenal arteries, obtaining the IRI using a simple method with the available ultrasound equipment. The IRI is the result of a complex interaction between the kidney and the systemic vessels. Although not fully understood, IRI is widely accepted as a useful tool for studying renal microcirculation and can provide diagnostic and prognostic information in many different settings ${ }^{39}$. However, a review study concluded that IRI is not specific for an individual disease; however, in a selected group of patients, it could be used as a good marker of cardiovascular-renal changes and a predictor of kidney events and mortality ${ }^{40}$.

The present study has some limitations: a) it is an observational and cross-sectional study; therefore, further prospective studies are necessary to assess whether the IRI can predict cardiovascular events in this population. b) the study included only individuals with high cardiovascular risk; hence, it is not possible to conclude whether this association also occurs in the population with low cardiovascular risk.

c) the study included a specific population of people of African descent who live in isolated communities; hence, this data cannot be extrapolated to the general population of African descent. d) there was no control group with non-Afro-descendant individuals.

\section{Conclusions}

In conclusion, an association was found between IRI and imaging biomarkers of cardiovascular risk, mainly coronary calcium score, diastolic dysfunction on Doppler echocardiography, and carotid atherosclerotic plaque, in individuals of Afro-descendant with a high cardiovascular risk. Further prospective studies are needed to ascertain whether IRI, as a non-invasive, inexpensive, and easy to perform test, can be used as a biomarker of cardiovascular risk clinical practice.

\section{List Of Abbreviations}

IRI: intrarenal resistivity index; CVD: cardiovascular disease; us-CPR: ultrasensitive C Reactive Protein; GFR glomerular filtration rate; CAC: coronary artery calcium; DM: Diabetes Mellitu; CKD: chronic kidney disease; BMI: Body Mass Index; LA: left atrium; CMIT: carotid intima-media thickness; LV: left ventricle; LAP: left atrial pressure.

\section{Declarations}

\section{Ethics approval and consent to participate}

The study was approved by the Research Ethics Committee of the University Hospital of the Federal University of Maranhão ( $\left.n^{\circ} 41,492 / 2012\right)$. All participants provided informed consent.

\section{Consent for publication}


Not applicable.

\section{Availability of data and materials}

The datasets used and analysed during the current study are available from the corresponding author on reasonable request.

\section{Competing interests}

The authors declare that they have no competing interests.

\section{Funding}

This study was funded by the Research Support Foundation of Maranhão (Fundação de Amparo a Pesquisa do Maranhão - FAPEMA).

\section{Authors' contributions}

All authors have contributed sufficiently to the project to be included as authors. NSF conceived the study concept and obtained funding. FLS designed, participated in the analysis and interpretation of data and wrote the main manuscript textand. DJB, JSL and VGM took responsibility for the integrity of the data. ECM reviewed the manuscript. FLS, NSF, DJB, VGM and JSL are responsible for data collection. All authors read and approved the final version to be published.

\section{Acknowledgements}

We are grateful to the participating PREVRENAL team for their precious technical work.

\section{References}

1. Yusuf S, Reddy S, Ounpuu S, Anand S. Global burden of cardiovascular diseases: part I: general considerations, the epidemiologic transition risk factors, and impact of urbanization. Circulation. 2001;104:2746-2753. doi: 10.1161/hc4601.099487

2. Gersh BJ, Sliwa K, Mayosi BM, Yusuf, S. The epidemic of cardiovascular disease in the developing world: global implications. European Heart Journal. 2010;31:642-648.

doi:10.1093/eurheartj/ehq030

3. Goff DC Jr, Lloyd-Jones DM, Bennett G, D'Agostino RB, Gibbons R, Greenland P, Lackland DT, Levy D, O'Donnell CJ, Robinson JG, Schwartz JS, Shero ST, Smith SC Jr, Sorlie P, Stone NJ, Wilson PW, Jordan HS, Nevo L, Wnek J, Anderson JL, Halperin JL, Albert NM, Bozkurt B, Brindis RG, Curtis LH, DeMets D, Hochman JS, Kovacs RJ, Ohman EM, Pressler SJ, Sellke FW, Shen WK, Smith SC Jr, Tomaselli GF. 2013 ACC/AHA Guideline on the Assessment of Cardiovascular Risk: A Report of the American College of Cardiology/American Heart Association Task Force on Practice Guidelines. Circulation. 2014;129:S49-S73. doi: 10.1161/01.cir.0000437741.48606.98 
4. Piepoli MF, Hoes AW, Agewall S, Albus C, Brotons C, Catapano AL, Cooney MT, Corrà U, Cosyns B, Deaton C, Graham I, Hall MS, Hobbs FDR, Løchen ML, Löllgen H, Marques-Vidal P, Perk J, Prescott E, Redon J, Richter DJ, Sattar N, Smulders Y, Tiberi M, van der Worp HB, van Dis I, Verschuren WMM, Binno S. 2016 European Guidelines on cardiovascular disease prevention in clinical practice: The Sixth Joint Task Force of the European Society of Cardiology and Other Societies on Cardiovascular Disease Prevention in Clinical Practice (constituted by representatives of 10 societies and by invited experts)Developed with the special contribution of the European Association for Cardiovascular Prevention \& Rehabilitation (EACPR). Eur Heart J. 2016;37(29):2315-2381. doi:

10.1093/eurheartj/ehw106.

5. Laurent S, Boutouvrie P. Arterial stiffness: a new surrogate end point for cardiovascular disease? J Nephrol. 200;71(suppl 12):S45-S50). doi: 10.1161/HYPERTENSIONAHA.112.194456

6. Hashimoto J, Ito S. Central Pulse Pressure and Aortic Stiffness Determine Renal Hemodynamics Pathophysiological Implication for Microalbuminuria in Hypertension. Hypertension. 2011;58:839846. doi: 10.1161/HYPERTENSIONAHA.111.177469

7. Pourcelot L. Applications Clinique de l'examen Doppler transcutane. In: Peronneau P (ed) Symposium: velocimetric ultrasonnordoppler. Inserm, Paris. 1974;213-240.

8. Ponte B; Pruijm M; Ackermann D; Vuistiner P; Eisenberger U; Guessous I; Rousson V; Mohaupt MG; Alwan H; Ehret G; Pechere-Bertschi A; Paccaud F; Staessen JA; Vogt B; Burnier M; Martin PY; Bochud $M$. Reference values and factors associated with renal resistive index in a family population study. Hypertension. 2014;63:136-142. doi: 10.1161/HYPERTENSIONAHA.113.0232

9. Okura T, Watanabe S, Miyoshi K, Fukuoka T, Higaki J. Intrarenal and carotid hemodynamics in patients with essential hypertension. Am J Hypertens. 2004;17(3):240-244. doi:10.1016/j.amjhyper.2003.10.005

10. Calabia J, Torguet P, Garcia I, Martin N, Mate G, Marin A, Molina C, Valles M. The Relationship Between Renal Resistive Index, Arterial Stiffness, andAtherosclerotic Burden: The Link Between Macrocirculation and Microcirculation. J Clin Hypertens (Greenwich). 2014;16:186-191. DOI: 10.1111/jch.12248

11. Geraci G, Mulè G, Geraci C, Mogavero M, D'Ignoto F, Morreale M, Foraci AC, Cottone S. Association of renal resistive index with aortic pulse wave velocity in hypertensive patients. Eur J Prev Cardiol. 2015;22(4):415-22. doi: 10.1177/2047487314524683

12. Geraci G, Mulè G, Costaza G, Mogavero M, Geraci C, Cottone S. Relationship Between Carotid Atherosclerosis and Pulse Pressure with Renal Hemodynamics in Hypertensive Patients. American Journal of Hypertension. 2016;29:519-527. doi: 10.1093/ajh/hpv130.

13. Kuznetsova T, Cauwenberghs N, Knez J, Thijs L, Liu YP, Gu YM, Staessen JA. Doppler indexes of left ventricular systolic and diastolic flow and central pulse pressure in relation to renal resistive index. Am J Hypertens. 2015;28(4):535-545. doi: 10.1093/ajh/hpu185

14. Pontremoli R, Viazzi F, Martinoli C, Ravera M, Nicolella C, Berruti V, Leoncini G, Ruello N, Zagami P, Bezante GP, Derchi LE, Deferrari G. Increased renal resistive index in patients with essential 
hypertension: a marker of target organ damage. Nephrol Dial Transplant. 1999;14:360-365. doi: 10.1093/ndt/14.2.360

15. Tadesco MA, Natale F, Mocerino R, Tassinario G, Calbrò R. Renal resistive index and cardiovascular organ damage in a large population of hypertensive patients. Journal of Human Hypertension. 2007; 21: 291-296. DOl:10.1038/sj.jhh.1002145.

16. Doi Y, Iwashima Y, Yoshirara F, Kamide K, Takata H, Fujii T, Kubota Y, Nakamura S, Horio T, Kawano Y. Association of Renal Resistive index With Target Organ Damage in Essencial Hypertension. Am J Hypertens. 2012;25(12):1292-1298. doi:10.1038/ajh.2012.113

17. Nosadini R, Velussi M, Brocco E, Abaterusso C, Carraro A, Piarulli F, Morgia G, Satta A, Faedda R, Abhyankar A, Luthman $\mathrm{H}$, Tonolo $\mathrm{G}$. Increased renal arterial resistance predicts the course of renal function in type 2 diabetes with microalbuminuria. Diabetes. 2006;55(1):234-239. doi:10.2337/diabetes.55.01.06.db05-0881

18. Hamano K, Nitta A, Ohtake T, Kobayashi S. Associations of Renal Vascular Resistance With Albuminuria and Other Macroangiopathy in Type 2 Diabetic Patients. Diabetes Care. 2008;31(9): 1853-1857. doi: $10.2337 /$ dc08-0168

19. Liu KH, Chu WCW, Kong APS, Ko GTC, Ma RCW, Chan JWS, So WY, Andrea Luk AOY, Cheung KKT, Ozaki R, Ahuja AT, Chan JCN. Intrarenal arterial resistance is associated with microvascular complications in Chinese type 2 diabetic patients. Nephrol Dial Transplant. 2013;28:651-658. doi: 10.1093/ndt/gfs471

20. Heine GH, Reichart B, Ulrich C, Köhler H, Girndt M. Do ultrasound renal resistance indices reflect systemic rather than renal vascular damage in chronic kidney disease? Nephrol Dial Transplant. 2007;22:163-170 doi:10.1093/ndt/gfl484

21. Yamaguchi Y, Akagaki F, Nakamori A, Sugiura T. Chronological renal resistive index increases related to atherosclerotic factors, and effect of reninangiotensin system inhibitors. Clin Exp Nephrol. 2018. doi: 10.1007/s10157-018-1667. [Epub ahead of print]

22. Frohlick ED. Hemodynamic differences between black patients and white patients with essential hypertension. State of the art lecture. Hypertension. 1990;15:675-680. doi: 10.1161/01.HYP.15.6.675

23. Kahn DF, Duffy SJ, Tomasian, D, Holbrook M, Rescorl L, Russell J, Gokce N, Loscalzo J, Vita JA. et al. Effects of Black Race on Forearm Resistance Vessel Function. Hypertension. 2002;40:195-201. doi: 10.1161/01.HYP.0000024571.69634.ED

24. Salgado-Filho N, Lages JS, Brito DJ, Salgado JV, Silva GE, Santos AM, Monteiro-Júnior FC, Santos EM, Silva AA, Araújo DV, Sesso RC. Prevalence of chronic kidney disease and comorbidities in isolated African descent communities (PREVRENAL): methodological design of a cohort study. BMC Nephrol. 2018 Feb 26;19(1):43. doi: 10.1186/s12882-018-0839-z.

25. Levey AS, Stevens LA, Schmid CH, Zhang YL, Castro AF 3rd, Feldman HI, Kusek JW, Eggers P, Van Lente F, Greene T, Coresh J; for the CKD-EPI (Chronic Kidney Disease Epidemiology Collaboration). A new equation to estimate Glomerular filtration rate. Ann Intern Med. 2009;150:604-12. doi: 10.7326/0003-4819-150-9-200905050-00006 
26. Silbiger JJ. Pathophysiology and Echocardiographic Diagnosis of Left Ventricular Diastolic Dysfunction. Echocardiogr. 2019;32:2216-32. doi: 10.1016/j.echo.2018.11.011.

27. Touboul PJ, Hennerici MG, Meairs S, Adams H, Amarenco F, Bornstein N, Csiba L, Desvarieux M, Ebrahim S, Hernandez Hernandez R, Jaff M, Kownator S, Naqvi T, Prati P, Rundek T, Sitzer M, Schminke U, Tardif JC, Taylor A, Vicaut E, Woo KS. Mannheim carotid intima-media thickness and plaque consensus (2004-2006-2011). An update on behalf of the advisory board of the 3rd, 4th and 5th watching the risk symposia, at the 13th, 15th and 20th European Stroke Conferences, Mannheim, Germany, 2004, Brussels, Belgium, 2006, and Hamburg, Germany, 2011. Cerebrovasc Dis. 2012; 34(4):290-6. doi: 10.1159/000343145

28. Azevedo FC, Rochitte CE, Lima JAC. Coronary Artery Calcium Score and Coronary Computed Tomographic Angiography for Cardiovascular Risk Stratification. Arq Bras Cardiol. 2012;98(6):559568. DOI:10.1590/S0066-782X2012000600012

29. Tublin ME, Bude RO, Platt JF. The resistive index in renal Doppler sonography: where do we stand? AJR Am J Roentgenol. 2003;180(4):885-92. doi:10.2214/ajr.180.4.1800885

30. Madubueze G, Ugwa E. A comparative ultrasonographic evaluation of intrarenal artery resistive index among hypertensive and normotensive adults in a black African population compared to a European population. Acta Radiologica Open. 2018;7(1):1-6. doi: 10.1177/2058460117752033

31. Florczak E, Januszewicz M, Januszewicz A, Prejbisz A, Kaczmarska M, Michałowska I, Kabat M, Rywik T, Rynkun D, Zieliński T, Kuśmierczyk-Droszcz B, Pregowska-Chwała B, Kowalewski G, Hoffman P. Relationship between renal resistive index and early target organ damage in patients with never treated essential hypertension. Blood Press. 2009;18(1-2):55-61. doi:

$10.1080 / 08037050902864078$

32. Geraci G, Mulè G, Mogaveo M, Geraci C, D'Ignoti D, Guglielmo C, Cottone S. Renal haemodynamics and severity of carotid atherosclerosis in hypertensive patients with and without impaired renal function. Nutr Metab Cardiovasc Dis. 2015 Feb;25(2):160-6. doi: 10.1016/j.numecd.2014.10.008

33. Quisi A, Kurt IH, Şahin DY, Kaypaklı O, Söker G, Kaya Ö, Allahverdiyev S, Genç Ö, Alıcı G, Koç M. Evaluation of the relationship between renal resistive index and extent and complexity of coronary artery disease in patients with acute coronary syndrome. Kardiol Pol. 2017;75(11):1199-1207. doi: 10.5603/KP.a2017.0138

34. Wybraniec MT, Bożentowicz-Wikarek M, Olszanecka-Glinianowicz M, Chudek J, Mizia-Stec K. Renal resistive index and long-term outcome in patients with coronary artery disease. BMC Cardiovascular Disorders. 2020;20:322. https://doi.org/10.1186/s12872-020-01607-w

35. O'Rourke MF, Safar ME. Relationship between aortic stiffening and microvascular disease in brain and kidney: cause and logic of therapy. Hypertension. 2005; 46(1): 200-204. doi: 10.1161/01. HYP.0000168052.00426.65)

36. Maclsaac RJ, Thomas MC, Panagiotopoulos S, Smith TJ, Hao H, Matthews DG, Jerums G, Burrell LM, Srivastava PM. Association between intrarenal arterial resistance and diastolic dysfunction in type 2 diabetes. Cardiovasc Diabetol. 2008 May 23;7:15. doi: 10.1186/1475-2840-7-15. 
37. Yeboah J, McClelland RL, Polonsky TS, Burke GL, Sibley CT, O'Leary D, Carr JJ, Goff DC, Greenland P, Herrington DM. Comparison of novel risk markers for improvement in cardiovascular risk assessment in intermediate-risk individuals. JAMA. 2012;308(8):788-95. doi: 10.1001/jama.2012.9624.

38. Adar A, Onalan O, Keles H, Cakan F, Kokturk U. Relationship between Aortic Arch Calcification, Detected by Chest X-Ray, and Renal Resistive Index in Patients with Hypertension. Med Princ Pract. 2018. doi: $10.1159 / 000495786$. [Epub ahead of print]

39. Nicolò PD, Granata A.Renal intraparenchymal resistive index: the ultrasonographic answer to many clinical questions. Journal of Nephrology. 2018. doi:10.1007/s40620-018-00567-x. [Epub ahead of print]

40. Lubas A, Kade G, Niemczyk R. Renal resistive index as a marker of vascular damage in cardiovascular diseases. Int Urol Nephrol. 2014;46(2):395-402. doi:10.1007/s11255-013-0528-6

\section{Figures}

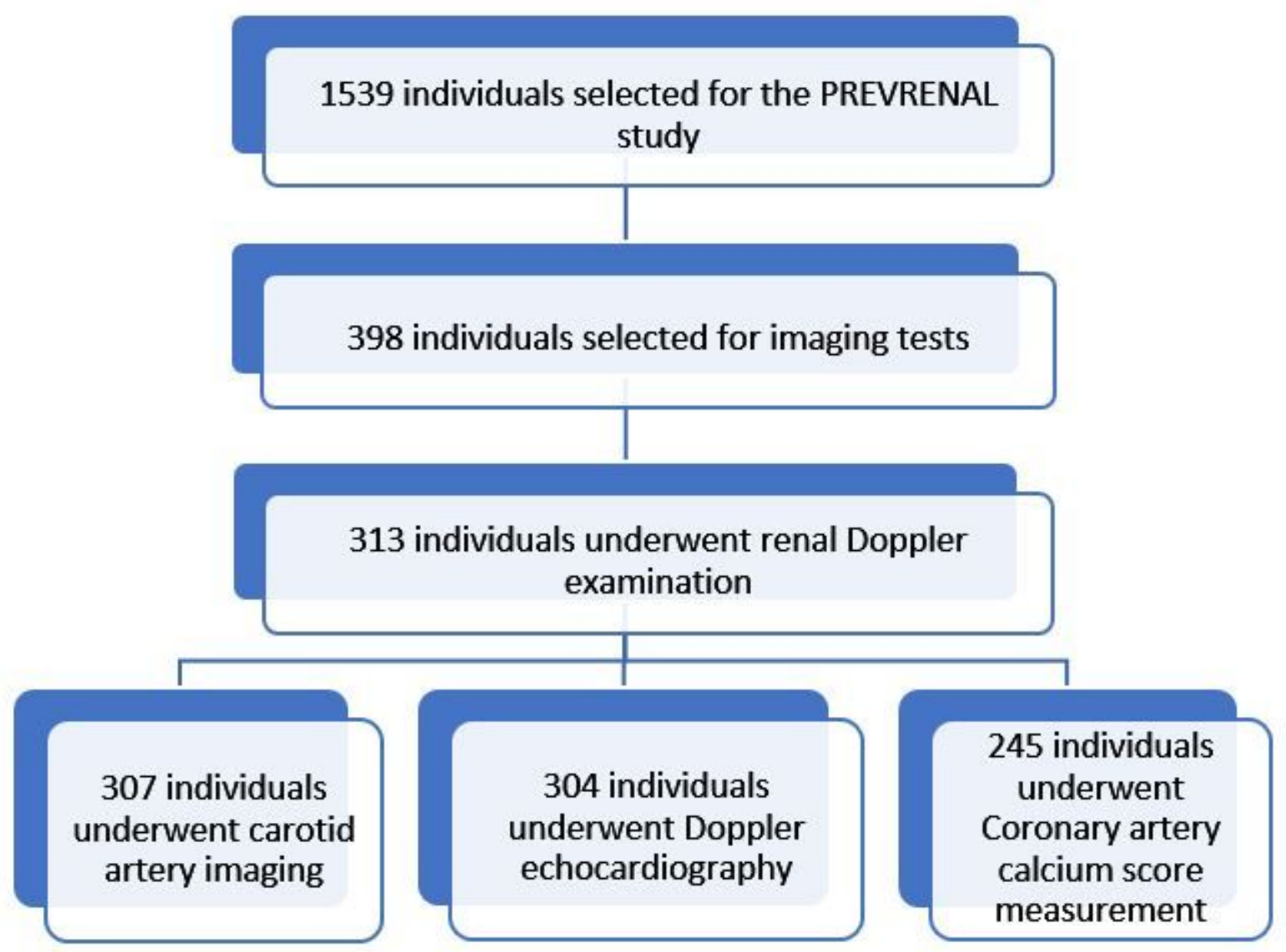


A sample of 398 individuals diagnosed with systemic arterial hypertension, diabetes mellitus type 2 , albuminuria, or GFR less than $60 \mathrm{~mL} / \mathrm{min} / 1.73 \mathrm{~m}^{2}$ was subjected to cardiovascular imaging tests. The cardiovascular imaging tests performed were transthoracic echocardiography, carotid duplex scan, chest computed tomography, and renal Doppler ultrasound. Among the individuals selected for imaging exams, 313 underwent and completed the renal Doppler ultrasound and thus made up the final sample of this study. Carotid duplex scan was performed in 307 individuals, 304 underwent a Doppler echocardiography, and 245 underwent a chest multidetector computed tomography (Figure 1). 